\title{
Effect Royal Jelly against Low Protein Diet Induced Hepatic Damage in Male Rats
}

\author{
Roshankhah Shiva', Arash Ziapoor², Cyrus Jalili ${ }^{3}$, Mohammad Reza Salahshoor ${ }^{1, *}$ \\ 'Department of Anatomical Sciences, Medical School, Kermanshah University of Medical Sciences, Kermanshah, IRAN. \\ ${ }^{2}$ Health Education and Health Promotion, Kermanshah University of Medical Sciences, Kermanshah, IRAN. \\ 'Medical Biology Research Center, Kermanshah University of Medical Sciences, Kermanshah, IRAN.
}

\begin{abstract}
Background: Proteins play the most important role in the structure and function of liver. Royal Jelly (RJ) as a honey bee secretion has antioxidant activities. This study was designed to evaluate the effects of RJ against hepatic damage in rats induced by Low Protein Diet (LPD). Materials and Methods: Forty-eight male rats were randomly assigned into 6 groups: sham and LPD (\%8 protein) groups; RJ groups $(200 \mathrm{mg} / \mathrm{kg}$ RJ for 5 months and $200 \mathrm{mg} / \mathrm{kg}$ RJ for 10 months, orally) and LPD + RJ groups $(200 \mathrm{mg} / \mathrm{kg}$ RJ orally + LPD for 5 months and $200 \mathrm{mg} / \mathrm{kg}$ RJ orally and LPD for 10 months). Griess technique was hired for determination of serum Nitric Oxide (NO) level. Aspartate Aminotransferase (AST), Alanine Aminotransferase (ALT) and Alkaline Phosphatase (ALP) concentrations were determined for liver functional disturbances value. In addition, Thiobarbituric acid reactive species, antioxidant capacity, the diameter of hepatocytes and the Central Hepatic Vein (CHV) were investigated. Results: LPD significantly increased the liver Malondialdehyde (MDA) and NO levels, the mean diameter of CHV and hepatocyte, hepatic enzymes and decreased tissue Ferric Reducing
\end{abstract}

Ability of Plasma (FRAP) level compared to the sham group $(P<0.01)$. The $\mathrm{RJ}$ and $\mathrm{RJ}+\mathrm{LPD}$ in all treatments significantly reduced the mean diameter of hepatocyte and $\mathrm{CHV}$, hepatic enzymes, liver MDA and NO levels and increased tissue FRAP level compared to the LPD group $(P<0.01)$. Conclusion: RJ administration recovers the hepatic injury due to oxidative stress by LPD in rats.

Key words: Low protein diet, Liver, Hepatoprotective, Royal jelly, Rats.

\section{Correspondence}

Dr. Mohammad Reza Salahshoor (PhD.), Department of Anatomical Sciences, Medical School, Kermanshah University of Medical Sciences, Kermanshah6715847141, IRAN.

Phone: 009809188360349

Email: reza.salahshoor@yahoo.com

DOI: 10.5330/ijpi.2019.1.2

\section{INTRODUCTION}

Increased production of Reactive Oxygen Species (ROS) induces the secretion of inflammatory cytokines and lipid peroxidation and elevates the production of NO in different tissues. ${ }^{1}$ Lipid peroxidation is an important factor involved in inducing oxidative damage in the cell membrane, lipoproteins and other lipid structures. ${ }^{2}$ Lipid peroxidation leads to the generation of peroxides and hydroxides, which causes toxicity in the body and a decline in antioxidant enzymes activity. ${ }^{3}$ This is a fact that liver has a life cycle for anatomical, biochemical and physiological evolution. It is not surprising that nutrition factors are considered to be effective in function and structure of liver. ${ }^{4}$ Nearly two third of metabolic items of the body are comprised of proteins. ${ }^{5}$ Roshankhah et al. showed that administration of LPD significantly had harmful effects of structure and function of brain in rats. ${ }^{6}$ LPD impairs the cells, cell membrane and DNA which leads to cell necrosis. ${ }^{7}$ Some factors such as the increased level of ROS production, inflammatory cytokines and NO are believed to be involved in LPD in different tissues. ${ }^{8} \mathrm{LPD}$ in long time causes oxidative stress, which is followed by the production of ROS such as superoxide radical and hydroxyl radical, induction of cell damage by biomembrane lipids destruction and disruption of cellular metabolism. ${ }^{9}$ The oxidative stress induced by lipid peroxidase production causes the hepatic cell membrane damage and triggers the activity of some hepatic enzymes. ${ }^{10}$ Presentation of antioxidant compounds can be an appropriate strategy to decrease the oxidative stress-induced damage. ${ }^{11} \mathrm{RJ}$ plays key roles in neonatal growth, completion of special sexual features and long life of the queen. Hypopharyngeal glands of honeybees by production of royal jelly play a crucial role in beehive development, especially queen. ${ }^{12}$
The bees feed by RJ in the first three days and their diet is changed afterward, while the queen always feeds by RJ. ${ }^{13} \mathrm{RJ}$ contains a wide range of chemical compounds such as Royalism (with potent antibacterial properties), Apisimin (stimulating the proliferation of monocytes in human), Jelleines (with antimicrobial activity) and lipids, fatty acids, carbohydrates, vitamins (B-group vitamins, thiamine, riboflavin, pentatonic acid, niacin, folic acid and biotin). ${ }^{14}$ The antioxidant activity of RJ inhibits the effects of oxidative stress and lipid peroxidation and protects DNA against oxidative stress. ${ }^{15}$ Kanbur et al. reported that mice fed with RJ had a higher level of 8- hydroxy-2-decenoic acid (oxidative stress marker) in their liver and blood serum, with increased average longevity. ${ }^{16}$ Further, Karadeniz et al. showed that the administration of RJ decreased liver toxicity and oxidative stress induced by cisplatin compounds. ${ }^{17} \mathrm{LPD}$ has toxic effects and RJ has numerous beneficial properties, especially antioxidant features. Further, no study has ever investigated the effects of RJ on the LPD-induced disorders of the liver. Hence, the present study was carried out to explore the effects of RJ on LPD -induced impairments of the liver of male rats.

\section{MATERIALS AND METHODS}

\section{Animals}

Animals were treated according to the guidelines of animal care and handling developed by the Iran 's Ministry of Health. Forty eight male Wistar rats (weighing 220-250 g) were purchased from Pastor Institute of Iran. The average age of the animals was two months ( 8 weeks). The animals were housed in standard cages (three per cage) with control 
conditions at $23 \pm 2^{\circ} \mathrm{C}$ and exposed to $12 \mathrm{hr}$ light/dark cycle in animal house of school of the medicine. . The animals were exposed to care facilities including water and food a week before treatment. All investigations conformed to the ethical and humane principles of research and were approved by the Ethics Committee of Medical Sciences (ethics certificate No.1398. 0161). ${ }^{11}$

\section{Groups and treatment}

Forty eight male rats were randomly divided into 6 groups (8 rats in each group). First group, the sham group that received a normal diet including $17.5 \%$ protein. Second group, the LPD group, a low protein diet was used; so that this diet merely included $8 \%$ protein. Base energy in both diets was similar. In the first group with normal diet, base energy was $2531 \mathrm{kcal}$ and in the second group with low protein diet, base energy was $2534 \mathrm{kcal}$. Third to four groups, the RJ administration groups (oral administration of $200 \mathrm{mg} / \mathrm{kg}$ RJ for 5 months and $200 \mathrm{mg} / \mathrm{kg} 10$ months). Five to six groups, LPD + RJ administration groups $(200 \mathrm{mg} / \mathrm{kg} \mathrm{RJ} \mathrm{+}$ LPD for 5 months and $200 \mathrm{mg} / \mathrm{kg}$ RJ + LPD for 5 months). ${ }^{6,16}$

\section{Dissection and sampling}

Rats related to each group were anesthetized with Ether inhalation. Venipuncture of the animals' hearts (right ventricle) was done using a $5 \mathrm{cc}$ syringe. The blood sample was incubated to make a clot for $15 \mathrm{~min}$ at $37^{\circ} \mathrm{C}$. Then the clot centrifuged to separate the serum at $3000 \mathrm{rpm}$ for $15 \mathrm{~min}$. The serum was stored at $-70^{\circ} \mathrm{C}$ for measurement of some biochemical parameters of the liver, NO level, oxidative stress and antioxidant capacity level. Then, the animals' liver fixed in $10 \%$ formalin solution for histological and morphometric investigations. ${ }^{1}$

\section{Oxidative stress}

In order to assess the oxidative stress by colorimetric analyze, the thiobarbituric acid reactive species were measured using Malondialdehyde (MDA) as the final product of lipid peroxidation of liver. In brief, three separate solutions each with a volume of $1400 \mu$ including acetic acid (Sigma, USA), TBA (Sigma, USA) and sodium dodecyl sulphate (Sigma, USA) were added to $100 \mu \mathrm{l}$ of liver homogenate and the mixture was stirred for $50 \mathrm{~min} .4 \mathrm{ml}$ of 1-butanol (Sigma, USA) was added to the combination and vortexed through centrifugation at $5000 \mathrm{rpm}$ for $15 \mathrm{~min}$. The absorbance of the higher layer was measured at $532 \mathrm{~nm}$ (Spectro; Germany) and sequential concentrations of tetraethoxypropane (Sigma, USA) were used as the external standard. The antioxidant capacity of the liver was measured using FRAP assay. The FRAP substance consisted of $30 \mathrm{ml}$ of acetate buffer (Sigma, USA) and $1.5 \mathrm{ml}$ chloride ferric (Sigma, USA). Briefly, $60 \mu \mathrm{l}$ of kidney homogenate was added to $1.5 \mathrm{ml}$ of newly prepared. FRAP substance (Sigma, USA) available in a test tube incubated at $37^{\circ} \mathrm{C}$ for $10 \mathrm{~min}$. The absorbance of the blue-colored complex was read against a blank at $593 \mathrm{~nm}$. Sequential concentrations of $\mathrm{FeSO}^{4} .7 \mathrm{H}^{2} \mathrm{O}$ (Sigma, USA) were used as an external standard. ${ }^{11}$

\section{Enzymes}

The liver was split and turned into a homogenous solution. To separate the biological enzymes, the obtained solution was centrifuged twice at $10,000 \mathrm{rpm}$ for $15 \mathrm{~min}$. The supernatant was separated for enzyme measurement. Alanine Aminotransferase (ALT) and Aspartate Aminotransferase (AST) activities were examined by the Reitman and Frankel method. Alkaline Phosphatase (ALP) activities were determined according to the procedure set out in the practical laboratory manual. ${ }^{2}$

\section{NO assay}

NO, measured by Griess assay according to the microplate technique. To measure the concentration of serum nitrite, the sample defroze and the supernatant ( $400 \mu \mathrm{l})$ was deproteinized by zinc sulfate under the condition of centrifugation ( $6 \mathrm{mg}$ zinc sulfate powder was mixed with $400 \mu \mathrm{L}$ serum and vortexed for $1 \mathrm{~min}) .100 \mu \mathrm{l}$ vanadium chloride, $50 \mu \mathrm{l} \mathrm{N}$-(1- naphthyl) ethylenediamine dihydrochloride (NEED) and $50 \mu \mathrm{l}$ sulfonamide solutions were added to the $100 \mu \mathrm{l}$ of the supernatant. Sodium nitrite $(0.1 \mathrm{M})$ was used for the standard curve and increasing concentrations of sodium nitrite $(5,10,25,50,75$ and $100 \mu \mathrm{M})$ were prepared. The Greiss solution was added to all microplates containing sodium nitrite and supernatant and finally, the reading was done through an ELISA reader (stat fax100. The USA) at the wavelength of $540 \mathrm{~nm} .{ }^{10}$

\section{Morphological and histopathological examinations}

In order to the histological evaluation of the hepatic structures, a piece of liver just $1 \mathrm{~cm}$ below the right lobe was removed in transverse section, washed in normal saline and fixed in $10 \%$ formalin. The sample dehydrated in ascending concentrations of ethanol, cleared by xylene solution and then embedded in paraffin. Thin sections $(4 \mu \mathrm{m})$ were cut using a microtome (Leica RM 2125, Germany) and stained with Hematoxylin and Eosin. For each hepatocyte, the full cellular area was measured. The hepatocyte outline was measured after capturing an image with a $\times 40$ objective lens. The maximum and minimum axis was measured for each hepatocyte to obtain the mean axis. At least 50 hepatocytes from each zone were measured in each liver. A separate measurement of $\mathrm{CHV}$ was performed using the same assay. The planning was examined with an Olympus) BX-51T-32E01 (research microscope connected to a DP12 Camera with a 3.34-million pixel resolution and Olysia Bio-software (Olympus Optical Co. LTD, Tokyo, Japan). ${ }^{3}$

\section{Statistical analysis}

After extracting the data, the Kolmogorov-Smirnov test was conducted first to confirm the data compliance of the normal distribution. One way analysis of variance (one-way ANOVA) was used for statistical analysis and Tukey post hoc test was used to determine the differences among the groups. SPSS 16 was used for data analysis and the results were expressed as mean \pm standard error and $P<0.05$ was considered significant.

\section{RESULTS}

\section{Oxidative stress}

The results of the oxidative stress testing showed that the liver MDA level significantly increased in the LPD group compared to the sham group $(P<0.01)$. The liver MDA level decreased significantly in all LPD + RJ groups compared to the LPD group $(P<0.01)$. Similarly, the LPD significantly decreased the liver FRAP level of the LPD group in comparison with that of the sham group $(P<0.01)$. Administration of RJ significantly increased the FRAP level in the liver in all LPD + RJ groups compared to the LPD group $(P<0.01)$. Treatment with RJ in all groups had no significant difference in the liver FRAPS and liver MDA levels compared to the sham group $(P>0.05)$ [Figure 1].

\section{Liver enzymes}

LPD led to a significantly increased in ALT, AST and ALP enzymes in comparison with the sham group $(P<0.01)$. The mean concentration of ALT, AST and ALP enzymes showed no significant difference in all RJ groups compared to the sham group $(P>0.05)$. Also, in all RJ and LPD+RJ groups significant decrease recorded in the mean of ALT, AST and ALP enzymes in comparison with the LPD group $(P<0.01)$ [Table 1].

\section{Nitrite oxide}

The results of blood serum NO measurement showed a significant increase in LPD group compared to the sham group $(P<0.01)$. The mean $\mathrm{NO}$ in the blood serum showed no significant difference in all RJ groups 
Table 1: Different hepatic enzymes between treatment groups.

\begin{tabular}{ccccccc}
\hline Enzymes $(\mathrm{ng} / \mathrm{ml})$ & Sham & LPD & \multicolumn{2}{c}{ RJ $(200 \mathrm{mg} / \mathrm{kg})$} & \multicolumn{2}{c}{$\mathrm{RJ}(200 \mathrm{mg} / \mathrm{kg})+\mathrm{LPD}$} \\
\hline & & & 5 months & 10 months & 5 months & 10 months \\
\hline AST & $76.93 \pm 2.20$ & $121.8 \pm 5.10^{*}$ & $76.33 \pm 3.40 \dagger$ & $74 \pm 2.010 \dagger$ & $95.4 \pm 5.20 \ddagger$ & $90.8 \pm 6.00 \ddagger$ \\
ALT & $35.49 \pm 2.50$ & $59.14 \pm 4.10^{*}$ & $34.91 \pm 2.50 \dagger$ & $33.7 \pm 1.10 \dagger$ & $38.7 \pm 5.01 \ddagger$ & $38.8 \pm 2.60 \ddagger$ \\
ALP & $2.14 \pm 0.10$ & $5.28 \pm 0.20^{*}$ & $2.05 \pm 0.30 \dagger$ & $2.1 \pm 0.50 \dagger$ & $3.05 \pm 0.30 \ddagger$ & $3.0 \pm 0.10 \ddagger$ \\
\hline
\end{tabular}

Data were presented as mean \pm standard deviation. ${ }^{*} P<0.01$ compared to the sham group. $\dagger P<0.01$ compared to LPD group. $\ddagger P<0.01$ compared to the LPD group. LPD: Low protein diet, RJ: Royal Jelly, ALP: Alkaline Phosphatase, ALT: Alanine Aminotransferase, AST: Aspartate Aminotransferase.


Figure 1: Comparison of LPD, sham and RJ groups of: (a) hepatic MDA level; (b) tissue FRAP level. *Significant different compared to the sham group $(P<0.01)$. †Significant different compared to the LPD group $(P<0.01)$. $\neq$ Significant different compared to the LPD group $(P<0.01)$. LPD: Low protein diet, $\mathrm{RJ}$ : RJ, MDA: Malondialdehyde, FRAP: Ferric reducing ability of plasma.

compared to the sham group $(P>0.05)$. Also, the mean of NO in blood serum significantly reduced in all RJ and LPD + RJ groups compared to the LPD group $(P<0.01)$ [Figure 2].

\section{Morphometric measurements}

The mean diameter of hepatocytes and CHV in experimental groups showed a significant increased between the sham group and LPD group $(P<0.01)$. The mean diameter of hepatocytes and $\mathrm{CHV}$ showed no significant difference in all RJ groups compared to the sham group $(P>0.05)$. Further, RJ and LPD+RJ significantly reduced the mean diameter of hepatocytes and $\mathrm{CHV}$ in all treated groups in comparison with the LPD group $(P<0.01)$ [Figure 3].

\section{Histopathological changes}

Histological analysis showed normal liver structure in the sham and RJ treatment group. After treatment with LPD in LPD group, the liver showed obvious changes and injuries. These anomalies included the increment in white blood cells (Inflammation), increased irregularities, sinusoidal dilatation and the vacuolization hepatocyte (necrosis). Treatment with LPD+RJ in all treated groups reduced the liver damage caused by the LPD [Figure 4].

\section{DISCUSSION}

LPD can induce a wide range of damages such as disruption in the development of central nervous system, impairment of renal system, Pancreatitis and etc. ${ }^{6,18}$ The findings of the current research suggesting that LPD has adverse and destructive effects on liver histology and function, oxidant-antioxidant imbalance as well and increase in NO level. On the other hand, the RJ as a natural antioxidant relief the side effects of LPD,

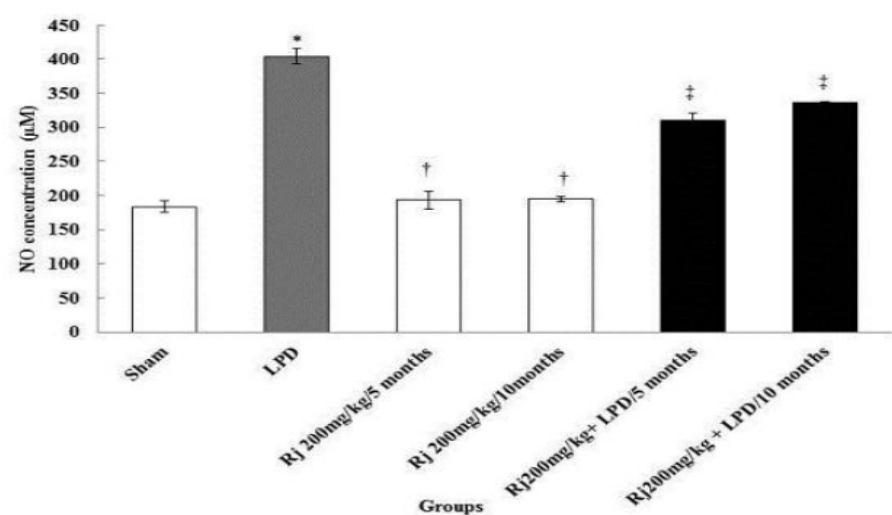

Figure 2: Effects of RJ, LPD and RJ + LPD on the mean of NO levels. * Significant different compared to the sham group $(P<0.01)$. + Significant different compared to the LPD group $(P<0.01)$. $\neq$ Significant different compared to the LPD group $(P<0.01)$. LPD: Low protein diet, RJ: RJ, NO: Nitric oxide.
A

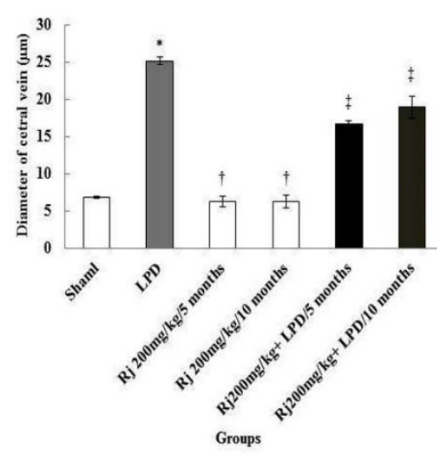

B

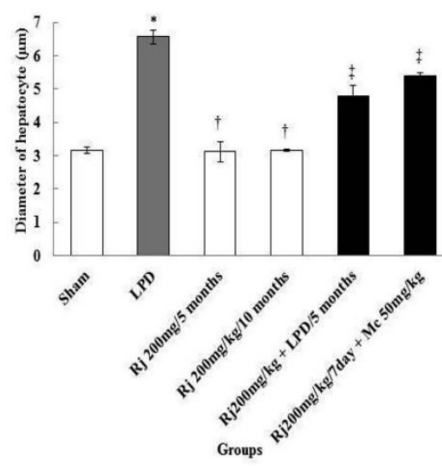

Figure 3: Effects of LPD, RJ and RJ + LPD on the CHV (A) and diameter of hepatocyte (B). *Significant different compared to the sham group $(P<0.01)$. †Significant different compared to the LPD groups $(P<0.01)$. $\neq$ Significant different compared to the LPD group $(P<0.01)$. LPD: Low protein diet, RJ: RJ, CHV: Central hepatic vein.

in particular, some liver parameters. It also recovers the cell damage offering by reduced MDA level, histology alterations and the rate of oxidation. The current study results also show that the $\mathrm{RJ}$ is able to reduce the lipid peroxidation (decreased MDA) and increase the antioxidant capacity of liver causing a reduction in oxidative stress. Consistent with these findings, a large body of studies has shown the anti-oxidant properties of RJ. ${ }^{15-17}$ RJ seems to inhibit the lipid peroxidation induced by Tert-Butyl hydroperoxide in the liver. ${ }^{19}$ Further, RJ is a lipophilic molecule that is able to inhibit the lipid peroxidation via Fenton reaction. ${ }^{16}$ 


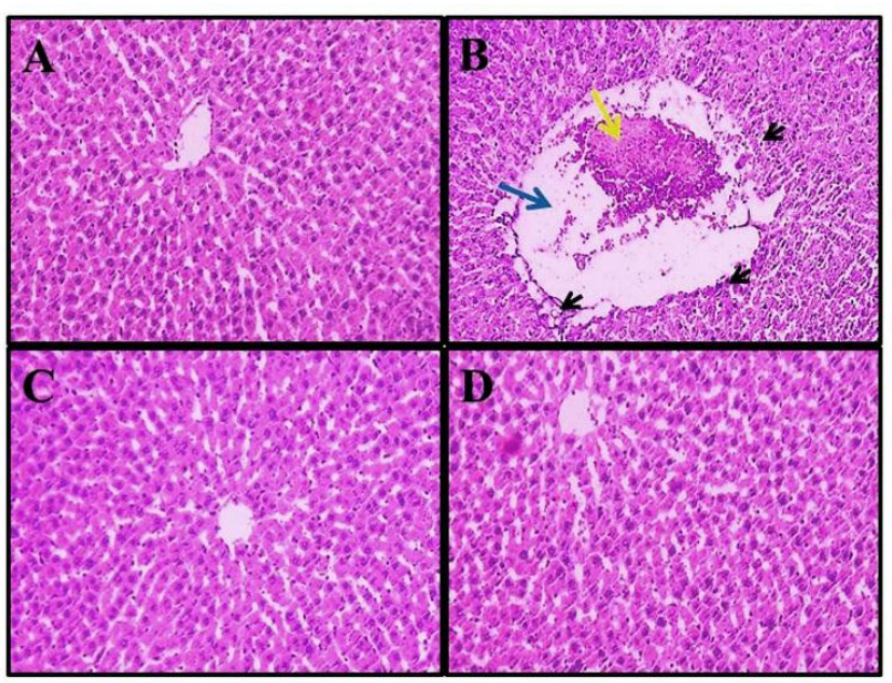

Figure 4: Microscopic images of liver of rats in different groups $(5 \mu \mathrm{m}, \mathrm{H}$ and E staining, $\times 100$ ). Micrograph of the liver section in the sham group (A), normal liver structure. Micrograph of the liver section in the LPD group (B), increased white blood and macrophage cells (Inflammation) (black arrows), $\mathrm{CHV}$ dilatation (blue arrow) and hyperemia (yellow arrow), due to the oxidative stress caused by LPD. Micrograph of the liver section in RJ $(200 \mathrm{mg} / \mathrm{kg} / 10$ months) group (C), normal liver structure. Micrograph of liver section in RJ + LPD (200 mg/kg/10 months) group (D), normal liver structure.

Hesami et al. showed that RJ attenuated the oxidative stress, blood glucose and lipid peroxidation in type II diabetic patients, which is in line with the results of the present study. ${ }^{20}$ Thus, it appears that RJ with its anti-oxidant properties could reduce the MDA in the treatment groups by inhibiting the production of ROS. The present study also indicates the recovery effects of RJ on some liver parameters as well as decreasing the oxidative stress due to the decline in MDA. The toxicity of LPD can lead to blood, biochemical and oxidative stress changes. Therefore, the mechanism of LPD is implemented by oxidative stress. ${ }^{6}$ The findings revealed that the number of hepatocytes in the LPD group has significantly decreased compared to the sham group whereas the CHV size has significantly increased. In addition, there is a significant increase in the number of hepatocytes and a significant decrease in the size of the CHV in all RJ and LPD + RJ groups compared to the LPD group. Another important finding is some changes observed in the liver in the LPD group including the enhanced state of the sinus spaces, macrophages accumulation around the $\mathrm{CHV}$ and the lymphoid cells penetrated in the portal space, as well as the CHV diameter enlargement. It seems that the invasion of free radicals to hepatic cells causes necrosis in cells of hepatic parenchyma. ${ }^{1}$ These cells can induce inflammatory responses in the liver, which leads to tissue damage by mononuclear inflammatory cells. The necrotic cells release pro-inflammatory mediators which can exacerbate the poison-induced liver injury. ${ }^{3}$ Apparently, macrophages are activated in response to tissue injury and release positive mediators, such as the alpha tumor necrosis factor (TNFa), interleukin-1 (IL-1) and NO. ${ }^{10}$ In the present study, the macrophages are actually the same as Copper cells located in the hepatic sinuses. It may seem that the Copper cells accumulation and the secretion of toxic mediators in these areas, with no symptoms of cell death, are involved in the presence of liver toxicity and necrosis. ${ }^{2}$ Moreover, free radicals' production and subsequent oxidative stress can be one of the most critical and essential causes of the liver cells death. ${ }^{1}$ The results corroborate the ideas of Menon et al. which suggested that the renal injuries and apoptosis induction in renal cells can be caused by LPD. ${ }^{21}$ LPD administration-induced of free radicals production may invade to hepatic cells and cause the necrosis in parenchymal cells. These cells can trigger the inflammatory responses in the liver and cause the invasion of mononuclear inflammatory cells to damaged tissue. The necrotic cells release the pro-inflammatory mediators and which can exacerbate the toxin-induced hepatic injuries. ${ }^{10}$ It may seem that the oxidative stress induced by LPD administration can produce active ROS with notable examples as hydroperoxides, singlet oxygen, hydrogen peroxide and superoxide that lead to the destruction of cell, DNA, proteins and intracellular lipids and ultimately leads to hepatic injury. ${ }^{22}$ RJ appears to carry out a protective effect against hepatic fibrogenesis. This effect is due to the following features as the polyphenol capacity, inhibitory effect on stellate cells activity, disorganization of the signal transduction pathways and expression of the cell cycle proteins. ${ }^{23}$ Stellate cells play a crucial role in the improvement of hepatic fibrosis and oxidative stress. $^{2}$ It seems that RJ with its capability can inhibit the P38MAPK phosphorylation in activated LPS of microglia. ${ }^{24} \mathrm{RJ}$ can exert its antiinflammatory effects on NF-K $\beta$ pathway. RJ can inhibit the NF-K $\beta$ by reducing $\mathrm{H} 2 \mathrm{O} 2$ production, inhibiting the $\mathrm{IK} \beta$ kinase, phosphorylation of P65 and depleting of P65. ${ }^{25}$ Silici et al. illustrated that RJ inhibits the induction of cisplatin-induced nephrotoxicity through the inhibition of oxidative stress, which is in line with the findings of the current study. ${ }^{26}$ The results of this study indicate that there are significant differences between liver antioxidant capacity and AST, ALT and ALP levels in the LPD group and the sham group. Similarly, there's a negative correlation in all treatments between hepatic antioxidant capacity in the LPD group and AST, ALT and ALP levels in the groups received RJ and LPD + RJ. The increase in the activity index of hepatic enzymes exist in serum indicates the liver injury in the current study. Moreover, the findings of Kanbur et al. confirmed the results of the current study in that the RJ could decrease the serum levels of ALT, AST and ALP. ${ }^{32}$ These enzymes can be released into the blood flow due to the incidence of necrosis or cell membrane damage. ${ }^{1}$ It may seem that LPD can induce damage to the cell membrane integrity by the inhibition of 1-4 respiratory chain complexes. ${ }^{27}$ The results are in agreement with Rebholz et al. findings which revealed that the LPD administration in male rats induces decreased functional of renal, increase creatinine and urea in serum blood and conversely reduce the total antioxidant capacity. ${ }^{28} \mathrm{RJ}$ appears to stabilize the cell membranes and prevents the enzymes leakage by lipid peroxidation prevention. ${ }^{15} \mathrm{RJ}$ can exert its antioxidant and antiinflammatory effects by inducing antioxidant enzymes, adjusting lipid metabolism and reducing lipid peroxidation. ${ }^{16}$ The results are consistent with the studies suggesting that administration of RJ reduces hepatic enzymes in diabetic rats and prevents hepatocytes injuries. ${ }^{29}$ The results of this study indicate a significant increase in the amount of NO in the serum of the recipient LPD group compared to the sham group. Furthermore, there is a significant decrease of serum NO level in LPD + RJ group compared to LPD group. It seems that oxidative stress available in cells increases the synthesis of NO synthase and consequently leads to an increase in nitrite production and decrease in cell survival. ${ }^{11}$ Due to the high consumption of oxygen, the mitochondrial dysfunction may increase the production of free radicals such as NO in most tissues of the body and also it may induce tissue injury especially in the liver due to the oxidative and nitrosative stress. ${ }^{1}$ Administration of LPD can significantly increase the amount of nitrotyrosine and NO biomarkers in the liver through the induction of oxidative stress. ${ }^{30}$ On the other hand, the antioxidants can damage and degrade the NO system (protein enzymes, substrates and cofactors), hence, reduces its production. ${ }^{2}$ The results are in agreement with the Momeni et al. findings which showed that the RJ can reduce NO in morphine-induced damage of liver. ${ }^{31}$ The results are in accordance with recent studies indicating that LPD by the means of oxidative stress induction is apparently able to damage and degrade hepatocytes, reduce antioxidant capacity and elevate serum levels of 
hepatic enzymes and NO. On the contrary, the RJ with a potent antioxidant property can reduce the detrimental effects of these destructive substances to some extent. Accordingly, the application of RJ can be a proper strategy to reduce the levels of free radicals and prevent the hepatic injuries of people who are exposed to LPD.

\section{CONCLUSION}

It appears that RJ may recover some hepatic damages in rats treated with LPD. Hence, the RJ could be considered to improve the histological and functional features of the liver exposed to LPD. The study approves that eliminated hepatic oxidant-antioxidant balance as molecular advocator due to the LPD would supervise the cellular chain reaction, observable either with light microscopy. However, supplementary studies are necessary to accurately describe the mechanisms of the action. RJ activates the oxidant system following LPD.

\section{Financial support and sponsorship}

We gratefully acknowledge the Research Council of Kermanshah University of Medical Sciences (No: 980161) for the financial support.

\section{CONFLICT OF INTEREST}

The authors declare no conflict of interest.

\section{ABBREVIATIONS}

RJ: Royal jelly; LPD: Low protein diet; NO: Nitric oxide; AST: Aspartate aminotransferase; ALT: Alanine aminotransferase; ALP: Alkaline phosphatase; CHV: Central hepatic vein; MDA: Malondialdehydep; FRAP: Ferric reducing ability of plasma; ROS: Reactive Oxygen Species; TNFa: Tumor necrosis factora; IL-1: interleukin-1.

\section{REFERENCES}

1. Salahshoor MR, Mohammadi MM, Roshankhah SH, Najari N, Jalili C. Effect of Falcaria vulgaris on oxidative damage of liver in diabetic rats. J Diabetes Metab Disord. 2019;18(1):15-23.

2. Zhu Z, Zhang Y, Wang J, Li X, Wang W, Huang Z. Characterization of sugar composition in Chinese royal jelly by ion chromatography with pulsed amperometric detection. J Food Compos Anal. 2019;78:101-7.

3. Salahshoor MR, Roshankhah S, Hosseni P, Jalili C. Genistein Improves Liver Damage in Male Mice Exposed to Morphine. Chin Med J. 2018;131(13):1598-604.

4. Plauth M, Bernal W, Dasarathy S, Merli M, Plank LD, Schütz T, et al. ESPEN guideline on clinical nutrition in liver disease. Clin Nutr. 2019;38(2):485-521.

5. Bjørnshave A, Holst JJ, Hermansen K. A pre-meal of whey proteins induces differential effects on glucose and lipid metabolism in subjects with the metabolic syndrome: a randomised cross-over trial. Eur J Nutr. 2019;58(2):755-64.

6. Roshankhah S, Sadeghi E, Jalili C, Salahshoor MR. Impacts of low-protein diet on the hippocampal CA1 neurons and learning deficits in rats. Adv Hum Biol. 2019;9(2):124-7.

7. DeMiranda MB, Lanna MF, Nascimento $A L$, DePaula CA, DeSouza ME Felipetto $\mathrm{M}$, et al. Hydroalcoholic extract of Brazilian green propolis modulates inflammatory process in mice submitted to a low protein diet. Biomed Pharmacother. 2019;109:610-20.

8. Darmon N, Pélissier MA, Heyman M, Albrecht R, Desjeux JF. Oxidative stress may contribute to the intestinal dysfunction of weanling rats fed a low protein diet. J Nutr. 1993;123(6):1068-75.

9. Gao X, Wu J, Dong Z, Hua C, Hu H, Mei C. A low-protein diet supplemented with ketoacids plays a more protective role against oxidative stress of rat kidney tissue with 5/6 nephrectomy than a low-protein diet alone. Br J Nutr. 2010;103(4):608-16.

10. Salahshoor MR, Khashiadeh M, Shiva R, Kakaberaei S, Jalili C. Protective effect of Royal jelly on liver toxicity induced by morphine. Res Pharm Sci. 2016;11(2):1209

11. Jalili C, Moradi D, Roshankhah SH, Salahshoor MR. Effect of pentoxifylline on kidney damage induced by nitrosamine in male rats. Res Pharm Sci. 2019;14(1):64-73.

12. Dalfardi M, Taghavi MM, Shariati KM, Taghipour Z, Nosratabadi R, Jalili C, et al. Protective and Modulatory Effects of Royal Jelly Used against the Induced Changes in Silver Nanoparticles on the Hippocampus of Male Rats. Nanomed J. 2019;6(2):136-41.

13. Hossen MS, Nahar T, Gan SH, Khalil M. Bioinformatics and Therapeutic Insights on Proteins in Royal Jelly. Curr Proteomics. 2019;16(2):84-101.

14. Viuda-Martos M, Ruiz-Navajas Y, Fernández-López J, Pérez-Álvarez JA. Functional properties of honey, propolis and royal jelly. J Food Sci. 2008;73(9):R117-24.

15. Maqsoudlou A, Mahoonak AS, Mora L, Mohebodini H, Toldrá F, Ghorbani M. Peptide identification in alcalase hydrolysated pollen and comparison of its bioactivity with royal jelly. Food Res Int. 2019;116:905-15.

16. Kanbur M, Eraslan G, Beyaz L, Silici S, Liman BC, Altınordulu S, et al. The effects of royal jelly on liver damage induced by paracetamol in mice. Exp Toxico Pathol. 2009;61(2):123-32.

17. Karadeniz A, Simsek N, Karakus E, Yildirim S, Kara A, Can I, et al. Royal jelly modulates oxidative stress and apoptosis in liver and kidneys of rats treated with cisplatin. Oxid Med Cell Longev. 2011;2011:1-10.

18. Bellizzi V, Dilorio BR, DeNicola L, Minutolo R, Zamboli P, Trucillo P, et al. Very low protein diet supplemented with ketoanalogs improves blood pressure control in chronic kidney disease. Kidney Int. 2007;71(3):245-51.

19. Almeer RS, Kassab RB, AlBasher GI, Alarifi S, Alkahtani S, Ali D, et al. Royal jelly mitigates cadmium-induced neuronal damage in mouse cortex. Mol Biol Rep. 2018;9:1-3.

20. Hesami S, Hashemipour S, Shiri-Shahsavar MR, Koushan Y, Haghighian HK. Administration of Iranian Propolis attenuates oxidative stress and blood glucose in type II diabetic patients: a randomized, double-blind, placebo-controlled, clinical trial. Caspian J Intern Med. 2019;10(1):48-54.

21. Menon V, Kopple JD, Wang X, Beck GJ, Collins AJ, Kusek JW, et al. Effect of a very low-protein diet on outcomes: long-term follow-up of the Modification of Diet in Renal Disease (MDRD) Study. Am J Kidney Dis. 2009;53(2):208-17.

22. Gansevoort RT, DeZeeuw D, DeJong PE. Additive antiproteinuric effect of ACE inhibition and a low-protein diet in human renal disease. Nephrol Dial Transplant. 1995; 10(4):497-504

23. Bilgic S, Dogan Z, Azirak S, Erdemli ME, Onderci M, Turk A, et al. Hepatoprotective effect of royal jelly, grape seed extract and Lycium barbarum against diethylnitrosamine-induced liver toxicity in rats. J Turgut Ozal Med Cent. 2018;25(3):342-8

24. Yang $X Y$, Yang DS, Wang JM, Li CY, Lei KF, Chen XF, et al. 10-Hydroxy-2-decenoic acid from Royal jelly: A potential medicine for RA. J Ethnopharmacol. 2010;128(2):314-21.

25. Dzopalic T, Vucevic D, Tomic S, Djokic J, Chinou I, Colic M. 3, 10-Dihydroxydecanoic acid, isolated from royal jelly, stimulates Th1 polarising capability of human monocyte-derived dendritic cells. Food Chem. 2011;126(3):1211-7.

26. Silici S, Ekmekcioglu O, Kanbur M, Deniz K. The protective effect of royal jelly against cisplatin-induced renal oxidative stress in rats. World $\mathrm{J}$ Urol. $2011 ; 29(1): 127-32$

27. Bellizzi V, Dilorio BR, DeNicola L, Minutolo R, Zamboli P, Trucillo P, et al. Very low protein diet supplemented with ketoanalogs improves blood pressure control in chronic kidney disease. Kidney Int. 2007;71(3):245-51.

28. Rebholz CM, Zheng Z, Grams ME, Appel LJ, Sarnak MJ, Inker LA, et al. Serum metabolites associated with dietary protein intake: Results from the Modification of Diet in Renal Disease (MDRD) randomized clinical trial. Am J Clin Nutr. 2019;109(3):517-25

29. Ghanbari $\mathrm{E}$, Nejati $\vee$, Khazaei M. Improvement in serum biochemical alterations and oxidative stress of liver and pancreas following use of royal jelly in streptozotocin-induced diabetic rats. Cell J. 2016;18(3):362-70.

30. Wu G, Flynn NE, Flynn SP, Jolly CA, Davis PK. Dietary protein or arginine deficiency impairs constitutive and inducible nitric oxide synthesis by young rats. J Nutr. 1999;129(7):1347-54.

31. Sugiyama T, Takahashi K, Kuzumaki A, Tokoro S, Neri P, Mori H. Inhibitory mechanism of 10-hydroxy-trans-2-decenoic acid (royal jelly acid) against lipopolysaccharide-and interferon- $\beta$-induced nitric oxide production. Inflammation. 2013;36(2):372-8 